\section{A alimentação do trabalhador no Brasil: um resgate da produção científica nacional}

\section{Worker diet in Brazil: a review of Brazilian scholarship on the topic}

Maria da Purificação Nazaré Araújo

Professora da Escola de Nutrição e pesquisadora do Grupo de Estudos e Pesquisa em Alimentação Coletiva /Escola de Nutrição/ Universidade Federal da Bahia (UFBA)

$$
\text { Escola de Nutrição/UFBA }
$$
Av. Araújo Pinto, 32

30275-170 - Salvador - BA - Brasil

puriaraujo@yahoo.com.br

\section{Jamacy Costa-Souza}

Professor da Escola de Nutrição e pesquisador do Grupo de Estudos e Pesquisa em Alimentação Coletiva/Escola de Nutrição/ Universidade Federal da Bahia (UFBA)

Escola de Nutrição/UFBA

Av. Araújo Pinto, 32

30275-170 - Salvador - BA - Brasil jamacy@ufba.br

Leny Alves Bomfim Trad

Professora do Instituto de Saúde Coletiva/UFBA

Av. Orlando Gomes, s/n

Cond. Parque Costa Verde, Q E, Lote 24

41650-010 - Salvador - BA - Brasil

trad@ufba.br

Recebido para publicação em maio de 2009.

Aprovado para publicação em junho de 2010.
ARAÚJO, Maria da Purificação Nazaré; COSTA-SOUZA, Jamacy; TRAD, Leny Alves Bomfim. A alimentação do trabalhador no Brasil: um resgate da produção científica nacional. História, Ciências, Saúde - Manguinhos, Rio de Janeiro, v.17, n.4, out.-dez. 2010, p.975-992.

\section{Resumo}

Empreende uma revisão de literatura sobre a alimentação do trabalhador no Brasil, questão importante para a saúde dos trabalhadores. Pretende oferecer elementos que permitam reflexão acerca do tema, procurando entender, sob uma perspectiva histórica, o tratamento que lhe foi dado. A pesquisa bibliográfica baseou-se sobretudo na Scientific Electronic Library On-line, cujos artigos sobre o tema foram analisados sem restrições quanto ao ano de sua publicação. Constatou-se, entre outros resultados, que o tema é rarefeito nos estudos de saúde do trabalhador, e que na nutrição as investigações são poucas, concentradas no Programa de Alimentação do Trabalhador, predominantemente de natureza quantitativa e desconsiderando a categoria 'processo de trabalho' nas análises.

Palavras-chave: alimentação do trabalhador; alimentação coletiva; saúde do trabalhador; nutrição; Brasil.

\section{Abstract}

Diet is a vital health question for workers. This review of the related literature sought to identify the elements that could contribute to an examination of the topic and help ascertain how it has been approached from a historical perspective. Our bibliographic research was based primarily on the Scientific Electronic Library On-line, from which pertinent articles were selected for analysis, without regard to year of publication. Among other findings, studies on worker health proved scarce; moreover, the few studies that have explored nutrition focus on the Worker's Food Program, primarily from a quantitative perspective and without taking the category of 'work process' into account in their analyses.

Keywords: worker diet; collective diet; worker health; nutrition; Brazil. 
$\mathrm{A}$ percepção de que o trabalho tem consequências sobre a saúde dos indivíduos é antiga, podendo ser encontrada, por exemplo, nas pesquisas de sociologia do trabalho de Friedmann e Naville (1962), em que são relatados os efeitos do trabalho na linha de montagem na França dos anos de 1950, ou nos estudos de Ramazzinni, considerado o fundador da medicina do trabalho no século XVIII (Merlo, Lápis, 2007). Entre os diferentes aspectos que podem incidir sobre a saúde dos trabalhadores, seja no ambiente fabril ou em outros setores da atividade produtiva, a questão da alimentação será aqui destacada, por ser reconhecida como uma dimensão da vida humana imprescindível para a sobrevivência básica, e comportar, ademais, dimensões sociais e simbólicas (Murrieta, 2001).

Ainda que a maioria dos artigos aqui revisados diga respeito ao Programa de Alimentação do Trabalhador (PAT) e, em quantidade menor, do Serviço de Alimentação da Previdência Social (Saps), curiosamente observa-se que o tema da alimentação tem sido pouco estudado na produção científica do campo da saúde do trabalhador.

A pouca produção de conhecimentos nessa área de investigação aponta em direção tanto a um problema como a um desafio para os estudiosos. Os estudos dirigem-se para duas direções: as relações entre trabalho e alimentação dos escravos, no passado longínquo da invisível senzala; e para os desafios impostos pelas mudanças observadas no mundo do trabalho e na alimentação das populações no presente, incluindo-se os impactos nas políticas públicas e na saúde dos trabalhadores. Entre esses extremos, faz-se necessário o resgate e a reinterpretação constantes dos fatos que marcaram essa trajetória, de modo a melhor compreender a alimentação como aspecto importante da saúde dos trabalhadores e, por conseguinte, construir subsídios que permitam uma maior reflexão acerca do tema.

O presente artigo é fruto de uma revisão da produção científica no campo da alimentação do trabalhador no Brasil, e procura entender o tratamento que lhe foi dado historicamente. Foi necessário abranger marcos históricos relevantes, tais como o período da escravidão, a era Vargas e a industrialização do país, o regime militar e a implantação do PAT, assim como os dias em curso.

A estratégia prioritária de busca incluiu pesquisa na Scientific Electronic Library Online (SciELO-Br). Utilizaram-se os termos: alimentação e trabalho; história da nutrição; história da alimentação; alimentação do trabalhador; trabalhadores; alimentação coletiva; programas de nutrição; programas e políticas de nutrição; e alimentação. Em um primeiro momento, selecionaram-se 54 artigos, sem restrição quanto ao tipo de estudo e período histórico analisado. Com base na leitura integral deles, destacaram-se 21, que apresentavam informações sobre alimentação do trabalhador. Desse total, 13 foram publicados no período de 2005 a 2008, sendo sete deles em 2007.

Foi, também, realizada busca manual, em caráter complementar, baseada principalmente em referências citadas nos artigos analisados. Tal estratégia permitiu acessar nove livros, oito artigos, três teses/dissertações e dois relatórios de pesquisa, que permitiram melhor compreender o período histórico estudado.

Apesar de reconhecer que podem ter ocorrido perdas no sistema de busca on line dos artigos, em virtude de contingências de indexação, e que tal opção não abarca a totalidade da produção bibliográfica brasileira nesse campo, acredita-se que o presente trabalho possa contribuir para sistematizar achados sobre aspectos importantes da alimentação do 
trabalhador no Brasil, bem como para subsidiar maior reflexão acerca da trajetória da alimentação coletiva, com foco na alimentação do trabalhador.

\section{Marco inicial - da senzala 'invisível' ao Serviço de Alimentação da Previdência Social}

O marco inicial para a construção do presente trabalho foi o trabalho escravo no Brasil. Observa-se certa invisibilidade histórica, no campo da nutrição, quando se trata da alimentação dos escravos e de sua relação com o processo de trabalho, dado que os artigos analisados, em sua maioria, contextualizam o tema tomando como ponto de partida a criação do Saps. Tal escolha, por parte dos autores, pode ser explicada pelo papel desse serviço no âmbito da alimentação do trabalhador brasileiro, uma vez que é considerado o primeiro órgão responsável por uma política social de alimentação no Brasil, sendo uma referência não apenas para a alimentação do trabalhador, mas também para a própria gênese do campo da nutrição brasileira.

Os escravos formaram os primeiros coletivos de trabalhadores agrícolas e das minas, nos serviços da era colonial. Antes de aportarem no Brasil, muitos morriam ainda nos navios negreiros, em virtude das péssimas condições em que eram transportados. Em que pese o fato de a alimentação do escravo no país não ter sido tema central dos artigos analisados, algumas publicações trazem questões importantes que serão aqui apresentadas. Pessoa (2005), por exemplo, em "O escravo negro nos primeiros escritos coloniais (15511627)", contabilizou sete citações em torno da alimentação dos escravos. Três delas, as que seguem, segundo o autor, estão no Tratado Descritivo do Brasil em 1587, de Gabriel Soares:

A primeira é sobre um tubérculo muito utilizado na ração dos moradores do Brasil, especialmente dos negros: da ilha de Cabo Verde e da de São Tomé foram à Bahia inhames que se plantaram na terra logo, onde se deram de maneira que pasmam os negros de Guiné, que são os que usam mais dele; e colhem inhames que não pode um negro fazer mais que tomar um às costas. Os dois trechos seguintes são sobre uma espécie de milho com ocorrência em todo o Brasil, denominado ubatim pelos índios: "milho de Guiné, que em Portugal chamam zaburro". A propósito de sua utilidade disse o letrado: "plantam os portugueses este milho para mantença dos cavalos e criação das galinhas e cabras, ovelhas e porcos; e aos negros de Guiné o dão por fruta, os quais o não querem por mantimento, sendo o melhor de sua terra". Acerca das espécies de bananas existentes na América Portuguesa: "há outra casta que os índios chamam pacobamirim, que quer dizer pacoba pequena, que são do comprimento de um dedo, mas mais grossas; essas são tão doces como tâmaras, em tudo mui excelentes". Sobre quem mais as tinham em boa conta como alimentação, disse o letrado: "os negros da Guiné são mais afeiçoados a estas bananas que às pacobas, e delas usam nas suas roças". Nem tudo na América Portuguesa, no entanto, em relação à alimentação, era 'tão doces como tâmaras, em tudo mui excelentes'... "os mantimentos, de que se sustentam os moradores do Brasil, brancos, índios e escravos de Guiné, são diversos, uns sumamente bons, e outros não tanto". Na base alimentar dos moradores do Brasil, por ordem de importância, estava: a mandioca, o arroz e o milho. O último desses alimentos interessa-nos particularmente, pois, "é mantimento mui proveitoso pera sustentação dos escravos de Guiné e Índios, porque se come assado e cozido e também em bolos, os quais são muito gostosos". O Aquês, uma espécie de coco, era um outro mantimento comum na dieta alimentar dos habitantes do Brasil, com qual se "sustenta grande parte do gentio da terra e dos negros de Guiné". Haveria, ainda, que 
mencionar os caranguejos, outro alimento da terra, que se tornaram o verdadeiro "sustento dos pobres, que vivem nela e dos índios, naturais e escravos de Guiné", como também a cana-de-açúcar, da qual se extrai um vinho "que para o gentio da terra e escravos de Guiné é maravilhoso" (p.35).

Pôrto (2006), ao estudar o sistema de saúde do escravo no Brasil do século XIX, relata que apesar do investimento representado por cada escravo, nem todos os proprietários cuidaram adequadamente da escravaria. Essa é uma questão que merece atenção: a contradição de se cuidar de uma 'coisa' que não é 'sujeito', pois o escravo é visto como mercadoria. Mas mercadoria tem valor. A partir da segunda metade do século XIX, com o maior controle sobre o tráfico de escravos, nota-se uma preocupação mais consistente dos senhores com a preservação da mão de obra escrava, já que a oferta se tornara mais escassa, mas não sua demanda, o que provoca a valorização do preço das 'peças'. Os proprietários procuram então dar melhor tratamento aos escravos, sem lhes reduzir a jornada de trabalho, numa tentativa de prolongar-lhes a vida útil. Essa é, no entanto, uma questão relativa que pode variar de acordo com a região, pois, apesar de constituirse como mercadoria investida de valor, nem sempre a situação do escravo era percebida como tal. Apesar de a saúde dos escravos ser precondição na fixação do seu valor, soluções baratas adotadas pelos proprietários de escravos, no fornecimento de moradia, alimentos, roupas ou remédios, fizeram proliferar doenças entre eles. As mais comuns eram as doenças decorrentes dos maus-tratos físicos ou do trabalho fatigante (p.1022).

Em dois, dos 21 artigos analisados para este estudo, há referências às pesquisas do oftalmologista Manoel Gama Lobo, de 1865, que constituem os primeiros relatos de casos de xeroftalmia (lesões de córnea) e hemeralopia (cegueira noturna) entre os escravos. A pesquisa traz relatos importantes sobre a alimentação da época (Vasconcelos, Santos, 2007; Vasconcelos, 2007). Vasconcelos e Santos (2007) salientam que o modelo de explicação de Da oftalmia brasiliana é nitidamente multicausal, pois envolve uma série de fatores relacionados às degradantes condições de vida dos escravos brasileiros. Entretanto, os autores observam um foco evidente na questão nutricional, fato que garante a primazia do estudo de Gama Lobo na história do campo da epidemiologia e da deficiência da vitamina A no Brasil. Sobre esse aspecto, os autores citam alguns trechos da publicação Da oftalmia brasiliana:

Pensamos que a causa desta oftalmia é a falta de nutrição conveniente e suficiente a que estão submetidos os escravos dos fazendeiros ... O trabalho excessivo, a alimentação insuficiente, os castigos corporais em excesso transformam estes entes miseráveis em verdadeiras máquinas de fazer dinheiro; sem direito de casamento, sem laço algum de amizade que os ligue sobre a terra, eles perdem o ânimo, sendo vítimas de opilações, úlceras crônicas, caquexias e todas as moléstias que são ocasionadas por uma alimentação insuficiente (Gama Lobo, 1865, p.432, citado em Vasconcelos, Santos, 2007, p.1346).

Assim, Gama Lobo salientava que a doença diferia entre as províncias, conforme o tratamento dado aos escravos. No Amazonas, Pará, Rio Grande do Sul e Mato Grosso, as doenças eram raras, a reprodução era abundante e a expectativa de vida, longa. Ali, os escravos eram mais bem tratados e se alimentavam melhor. Exemplifica que, na província do Pará, eles almoçavam chocolate e café, jantavam carne ou peixe com farinha de mandioca, comiam frutas e tinham o peixe como ceia. Já em outras províncias, principalmente aquelas 
produtoras de café e açúcar, os escravos eram mal tratados, a maior parte deles apresentavam doenças como úlceras crônicas nos olhos, cegueira noturna e, por consequência, havia maior mortalidade e frequência de abortos. Em relação à dieta, descreve que se alimentavam exclusivamente de feijão sem gordura e farinha de milho, e que raras vezes comiam carne ou peixe (Vasconcelos, Santos, 2007). Ou seja, uma dieta bastante pobre em termos nutricionais.

As informações trazidas pelos trabalhos de Gama Lobo são esclarecedoras quanto à discordância entre dois autores importantes da história da alimentação no Brasil, Gilberto Freire e Josué de Castro, no que diz respeito à situação alimentar do escravo brasileiro. Tal discordância foi discutida em artigo publicado de Vasconcelos (2001) e retomado em Vasconcelos, Santos (2007):

Freyre afirma que em relação à quantidade, os "mais bem alimentados", em geral, eram as duas classes antagônicas: os brancos das casas-grandes (senhores) e os negros das senzalas (escravos). Nesse aspecto, ele argumenta que a alimentação farta e reparadora dispensada pelos senhores de engenho aos escravos no Brasil tinha por objetivo obter do escravo negro, comprado caro, o máximo de esforço útil e não simplesmente o máximo de rendimento ... Josué de Castro, por sua vez, questiona a tese de que os "mais bem alimentados" fossem o senhor de engenho e o escravo e que o senhor alimentava bem o escravo para que ele produzisse mais ... Procura demonstrar que, além dos interesses econômicos subjacentes na ação do senhor de engenho, ao fornecer ao escravo maior teor energético (maiores quantidades de combustível), não havia preocupação com o fornecimento dos alimentos protetores, responsáveis pelos reparos e manutenção da "máquina de combustão", fazendo com que as senzalas fossem o espaço de "afecções nutritivas, avitaminoses, tuberculose e tantos outros males habituais" (p.1349).

Não deixa de ser instigante o fato de que o princípio a nortear as afirmações de Freire e Castro, numa análise mais acurada, está em consonância com as políticas públicas de alimentação do trabalhador, quer no longínquo Saps ou no atual Programa de Alimentação do Trabalhador (PAT), qual seja, o de alimentar para produzir e, de certa forma, a partir de um cardápio 'imposto' pela empresa.

Câmara Cascudo (2004, p.202), por sua vez, diz que se tem a impressão de que o escravo teve a alimentação relacionada com sua atividade essencial. Escravos dos engenhos de açúcar, escravos das fazendas de gado, escravos da mineração, escravos dos cafezais e escravos urbanos não deviam ter a mesma dieta. Assim, os escravos, para se alimentarem, ficavam à mercê de seus senhores e na dependência do entendimento dos mesmos quanto ao papel da alimentação na produtividade no trabalho. Ainda que se possa considerar, tendo em vista os registros históricos, que houve possivelmente luta e resistência por parte dos escravos para manutenção dos seus hábitos alimentares, o acesso ao material analisado não nos permite achados conclusivos sobre o período. Diante dos escassos artigos no campo da nutrição que consideram a alimentação do escravo no Brasil, e de informações apreendidas da história da era colonial, é apenas possível apropriar-se de algumas das questões aqui sinalizadas. No entanto, cabe registrar o desafio na busca e análise de outras fontes de dados pelos historiadores da alimentação no Brasil.

Já no início do século XX, mais especificamente entre 1911 e 1919, no bojo da economia capitalista exportadora cafeeira, os movimentos reivindicatórios que pleiteavam o 
fornecimento de serviços médicos aos trabalhadores nas fábricas podem ser entendidos como um projeto da própria classe empresarial, com dupla intenção. Primeiramente, para conter conflitos e tensões que ameaçavam despontar na classe operária; segundo, sendo o trabalho do imigrante essencial à implantação da produção desejada, era necessário criar condições que atraíssem e retivessem o trabalhador estrangeiro. Assinala-se, no período, a instalação de outros benefícios, como creches e restaurantes para fornecimento de alimentação ao trabalhador a preço de custo (Braga, Paula,1981).

Data de junho de 1917 a criação do Comitê de Defesa Proletária, integrado por líderes sindicais e de associações populares, para encaminhamento de reivindicações conjuntas, entre as quais se destacavam propostas voltadas para melhorias das condições de trabalho, aumento salarial e aspectos referentes à alimentação (Possas, 1981). As décadas posteriores, de 1930, 1940 e 1950 são consideradas o período básico de implementação do sistema industrial brasileiro, quando se observa uma rápida e profunda divisão do trabalho. Além disso, as relações trabalhistas estabelecidas se configuravam, então, em um cenário de luta política.

As aceleradas transformações socioeconômicas desencadeadas nos anos 1930, as quais conformaram a base urbano-industrial do país, apoiaram também processos de reorganização do Estado nacional. Educação, saúde, previdência, assistência social e programas de alimentação e nutrição, habitação popular, saneamento e transporte foram gradativamente se tornando alvo da ação pública (Draibe,1994).

No que tange especificamente à alimentação do trabalhador, registra-se, na década de 1930, a pesquisa coordenada por Josué de Castro, “As condições de vida das classes operárias no Recife". Os dados do estudo, considerado o primeiro inquérito dietético-nutricional do país, tiveram ampla divulgação nacional e provocaram a realização de investigações similares, inclusive a que serviu de base para a regulamentação da lei do salário mínimo e a formulação da chamada ração essencial mínima, estabelecida no decreto-lei 399, de 30 de abril de 1938 (Vasconcelos, 2007, 2002). Entre tão vasta gama de resultados, pode-se destacar a informação de que a dieta era formada de farinha com feijão, charque, café e açúcar. Verificou-se alto consumo de carboidratos e baixo consumo de lipídios, proteínas, minerais e vitaminas. Em relação ao consumo calórico, este se apresentava, em média, aproximadamente mil quilocalorias a menos do que o recomendado para um adulto normal. O custo da alimentação era de cerca de $71,6 \%$ do salário. A dieta insuficiente gerava alta mortalidade e baixa expectativa de vida (Castro, 1961). Josué de Castro retrata a fome pela qual passavam os trabalhadores da zona açucareira nordestina e, com ela, a suposta explicação para sua baixa capacidade de trabalho em relação aos de outras regiões do país.

Importa assinalar que o estudo acima referido foi desenvolvido em 1933 e tinha por objetivo traçar um plano de melhoria da alimentação do povo brasileiro. Após esse trabalho encontram-se, na imprensa nacional, artigos sobre o papel da alimentação e sua relação com a saúde e, sobretudo, sobre as relações entre alimentação, salário e política salarial. Novas pesquisas foram desenvolvidas a partir de então, despertando, de alguma forma, a consciência nacional para o angustiante problema da nutrição e suas implicações no processo produtivo, o que gerou a necessidade de o Estado intervir, com vistas ao estabelecimento do que, embora incipiente, se pode denominar política salarial (Castro, 
1977). Um estudo, entre os que enfatizavam os aspectos sociais e políticos da problemática alimentar no Brasil foi realizado em São Paulo, ainda na década de 1930, com o objetivo de investigar os gastos para alimentar 460 famílias de um bairro da capital paulista e avaliar, a partir desses dados, suas condições de acesso à alimentação (L'Abbate, 1988).

Diante desse cenário, o Estado avaliava a melhor maneira de garantir maior controle sobre a classe trabalhadora, de modo a amenizar os conflitos. Castro (1977) considera que a primeira atitude real no campo político ocorre quando a Constituição de 1934, em seu artigo 121, destaca a importância de se pagar um 'salário mínimo' capaz de satisfazer, conforme a condição de cada região, as necessidades normais do trabalhador. A mesma autora informa que publicações da época salientavam que, embora a pesquisa do Serviço de Estatística e Previdência do Trabalho anunciasse que o salário-mínimo beneficiaria mais de $58 \%$ da população operária, verificava-se, já na época de sua instituição, que mais de $60 \%$ do mínimo seriam gastos com alimentação se o trabalhador, e só ele, comesse a ração-tipo estabelecida pelo decreto-lei 399 como indispensável à subsistência. Por outro lado, a existência, desde então, de expressivo número de trabalhadores informais e desempregados nos centros urbanos indicava um inequívoco processo de exclusão.

Fica, pois, evidente que a instituição do salário-mínimo não conseguiria, já naquela época, resolver os problemas tal como se propunha, principalmente os relacionados à alimentação do trabalhador. Em 1939, por meio do decreto-lei 1.238, os estabelecimentos em que trabalhavam mais de quinhentos funcionários ficavam obrigados a destinar local abrigado, higiênico e devidamente aparelhado para os trabalhadores fazerem suas refeições. Em 1940 o Saps foi instituído, com o objetivo principal de propiciar aos trabalhadores alimentação adequada e com baixo custo, mediante instalação e funcionamento de restaurantes a eles destinados. Cabia às empresas, segundo o decreto-lei 1.238, o fornecimento de alimentos nos refeitórios. Além disso, cabia ao Saps atuar na sensibilização dos empregadores quanto à importância de oferecer alimentação aos seus trabalhadores.

Ao que parece, as empresas não atenderam prontamente a tal determinação. Rodrigues (2007), por exemplo, ao apresentar os achados de um trabalho conduzido em 1943 por Maria Thereza Nogueira Garcez, da Divisão de Estatística e Documentação Social da Prefeitura de São Paulo, aponta condições adversas da alimentação dos trabalhadores naquela época:

\footnotetext{
No grupo de trabalhadores fabris, moradores de 22 bairros da capital e de dois municípios vizinhos, mais de $80 \%$ dos entrevistados alimentavam-se no trabalho, mas nenhuma das indústrias que empregavam esses operários dispunha de instalações como restaurantes ou cozinhas: "a alimentação ele [o operário] a traz consigo ao vir para o trabalho, o que é mais frequente, ou recebe de casa à hora do almoço". No interior da fábrica, sequer havia refeitórios ou outros espaços, para serem usados na hora das refeições, pois os operários almoçam, na maior parte das vezes, desabrigados, em péssimas condições higiênicas e sem o menor conforto (sentados pelas sarjetas, sem água para lavar as mãos, estirados ao longo das calçadas) (p.249).
}

Em 1943 o Saps teve ampliadas suas responsabilidades no âmbito da criação de cursos técnicos e profissionais para formação de pessoal apto às atividades de nutrição, as visitadoras de alimentação, que tinham como principal atribuição levar noções de nutrição aos lares dos trabalhadores (Castro, 1977). Naquele período veiculava-se que a ignorância da 
população quanto à sua própria alimentação era uma das causas dos problemas alimentares (Rodrigues, 2007). Assim, a estratégia de educar a população pode ser vista como uma alternativa para camuflar outras questões importantes no enfrentamento da problemática da fome no país.

Em 1946 fundou-se o Instituto Nacional de Nutrição, e no mesmo ano foi criado o plano Salte - Saúde, Alimentação, Transporte e Energia -, do governo Dutra (Silva Júnior, 1998). Em 1947, em São Paulo, um grupo de empresários criou o Serviço Social da Indústria (Sesi), com o objetivo de promover as condições sociais de trabalhadores, entre as quais as de alimentação. À Divisão de Assistência Social do Sesi caberia fornecer "refeição racional", vinculada à educação alimentar, aos trabalhadores (Gambardella, 1990).

Em termos políticos, a internacionalização da produção brasileira remonta ao Plano de Metas implantado no governo de Juscelino Kubitscheck (1956-1961). Anteriormente, podese caracterizar tal produção como constituída basicamente de capital nacional. Com a temática 'desenvolvimentista', foi crescente a injeção de capital estrangeiro na economia brasileira, visando ao financiamento da industrialização. Como assinala Vargas (1985), nesse período ampliou-se a difusão das técnicas tayloristas, cujos princípios tinham sido disseminados no período anterior.

Concomitantemente, seria tentada a adequação do 'dentro' e do 'fora' da fábrica, subordinada à nova exigência de economia de tempo. Como boa parte das empresas implantadas no país era multinacional, principalmente as do setor automobilístico, elas traziam novos processos produtivos e padrões de organização do trabalho. No mesmo sentido, com a tendência de os centros industriais se localizarem distantes da área urbana, houve o aumento do trajeto entre a residência e o trabalho, sendo de primordial importância a oferta da alimentação por parte das empresas, já que não havia mais a possibilidade de o trabalhador receber suas refeições de casa, à hora do almoço.

Acrescentando-se às atribuições do Saps referidas, podem-se assinalar outras que mostram a magnitude das responsabilidades que, ao longo do tempo, a instituição foi absorvendo: pesquisas na área de alimentação e nutrição e de divulgação científica; oferta do desjejum escolar aos filhos dos trabalhadores, uma iniciativa que foi fruto de uma pesquisa junto às famílias e na qual ficou constatado que muitas crianças iam para as escolas tendo ingerido apenas uma xícara de café (a medida pode ser considerada o embrião do que posteriormente seria a merenda escolar); auxílio alimentar ao trabalhador e a sua família durante trinta dias, em caso de doença ou desemprego; assistência por intermédio da seção de emprego e do ajustamento dos trabalhadores desocupados ou atingidos por doença ou invalidez parcial; biblioteca e sala de leitura destinadas aos trabalhadores; aulas de costura para as filhas dos operários; aulas noturnas de alfabetização; realização de cursos formadores de nutricionistas, nutrólogos e profissionais de copa e cozinha (Castro, 1977).

Vasconcelos (2005) ressalta que na sequência entre o Plano Salte de Gaspar Dutra (19461950), o retorno do populismo de Getúlio Vargas (1951-1954), o desenvolvimento rápido do Plano de Metas de Juscelino Kubitschek (1955-1960) e as reformas de base de João Goulart (1961-mar. 1964), a questão da intervenção estatal em alimentação e nutrição materializou-se pela continuidade das ações do Saps. 


\section{O Programa de Alimentação do Trabalhador (PAT)}

O Programa de Alimentação do Trabalhador (PAT), juntamente com o Programa Nacional de Alimentação do Escolar (Pnae), popularmente conhecido como Merenda Escolar, são os mais antigos programas de suplementação alimentar em vigência no Brasil. Pode-se considerar que os dois tiveram suas bases lançadas ainda na época do Saps: o PAT, pelas razões óbvias da oferta de alimentação aos trabalhadores; e o Pnae, pela oferta do desjejum escolar aos filhos dos trabalhadores.

Em 1964 o Brasil retornava à ditadura. Segundo Braga e Paula (1981), os gastos federais em saúde pública, sobretudo em ações de natureza preventiva, decresceram sensivelmente em relação aos anos anteriores, contrapondo-se ao aumento do aporte finaceiro na assistência médica-previdenciária, resultante da majoração da carga tributária previdenciária, que, no limite, terminava por ser financiada basicamente pelos assalariados.

Esse período (final dos anos 1960 e início dos 1970), cumpre salientar, foi marcado pela organização e pelo crescimento de movimentos de oposição ao regime militar. No plano internacional, o debate sobre a fome mundial despontou com força no início dos anos 1970. Realizaram-se vários eventos chamando a atenção para a "fome mundial de alimentos". A Organização das Nações Unidas Para Agricultura e Alimentação (FAO, na sigla em inglês) divulgou, então, inúmeros dados mostrando a quantidade de energia e proteína consumidas pelos povos dos países dependentes. E estudo realizado no Nordeste brasileiro revelou que os mais pobres se encontravam nos limites da sobrevivência, enquanto os ricos se nutriam com cerca do dobro de suas necessidades diárias (Bosi, 1988).

Ainda na década de 1970, com a criação do Instituto Nacional de Alimentação e Nutrição (Inan) e, com ele, os I e II Programa Nacional de Alimentação e Nutrição (Pronan), foi instituído o PAT, com os custos divididos entre trabalhador, empresa e governo. No documento técnico do Ministério do Trabalho, datado de 1979, "Incentivos fiscais para alimentação do trabalhador", que compõe a Coleção VII - Promoção Social, os objetivos principais do PAT estavam assim definidos: "Proporcionar disponibilidade maior e mais eficiente de energia para o trabalho do homem e, consequentemente, concorrer para melhoria do estado nutricional do trabalhador; dividir, transitoriamente, entre o governo, a empresa e o trabalhador, o custo da energia humana necessária para o trabalho" (Brasil, 1979, p.6). Assim, a alimentação não é tida como um direito do trabalhador, mas sim como um 'combustível' necessário ao 'trabalhador-máquina' e, inclusive, deveria custeá-la em parte. Essa temática percorre toda a trajetória do PAT, que mesmo usando terminologias distintas apresenta, ao longo do tempo, a mesma abordagem: "ao criar o Programa, visou o Governo não somente facilitar a vida do trabalhador brasileiro, como também obter outros benefícios, quais sejam mais saúde para o operário, maior produtividade, diminuição dos acidentes de trabalho e menor índice de absenteísmo e rotatividade de mão de obra nas empresas" (Brasil, 1987, p.60).

O PAT surgiu em uma época em que, no Brasil, a discussão no campo da nutrição girava predominantemente em torno da desnutrição calórica e proteica, e das carências nutricionais específicas (mais voltada para a população materno-infantil). Segundo Peliano e colaboradores (1985, p.31), na redação do Programa aparece a seguinte justificativa para inserção 
dos trabalhadores como público-alvo: "Embora não sendo a maior prioridade do ponto de vista biológico, constitui-se a desnutrição do adulto, quando este é o chefe da família, a de maior repercussão social: a diminuição ou supressão de seus rendimentos afeta decisivamente a capacidade de sobrevivência do grupo familiar".

Pode-se vislumbrar que a prioridade na suplementação alimentar dos trabalhadores não se esgotava, apenas, na preocupação com o grupo familiar. Já se reconhecia a necessidade de alimentar melhor a classe trabalhadora para garantir maior produtividade, tendo em vista as alternativas apresentadas anteriormente à criação do PAT. A respeito dos primórdios do Pronan, Coimbra (1985, p.9) afirma: "na política como um todo, a clara primazia financeira está no PAT, que mobiliza sozinho bem mais que o dobro da soma de todos os outros" - possivelmente dada a esperada repercussão na produtividade do trabalhador, uma vez ser este peça fundamental na implantação e manutenção do modo de produção capitalista.

A empresa que adere ao programa é incentivada, por meio de renúncia fiscal, e deve fornecer aos seus trabalhadores (prioritariamente os de baixa renda, ou seja, aqueles que recebem até cinco salários mínimos) refeições ou cupons/cartões que lhes permitam adquirir refeições em restaurantes ou alimentos em mercados credenciados, ou ainda cestas de alimentos, sempre baseadas em recomendações nutricionais mínimas estipuladas pelo Programa.

Em que pese o fato de ter sido instituído como programa emergencial e transitório para combater a desnutrição calórica proteica, o PAT continua em vigência, com o desafio de melhorar o estado nutricional dos trabalhadores, que na atualidade, em sentido oposto ao que orientou sua criação, apresentam um perfil de excesso de peso, com sérios riscos para o desenvolvimento de doenças crônico-degenerativas. Esse é um dado importante para os estudos em políticas públicas em nutrição. De todas as estratégias de intervenção daquele período inicial, incluindo o próprio Inan, apenas o PAT e a Política Nacional de Alimentação e Nutrição (Pnan) permanecem em vigor. A compreensão de tal vitalidade não está evidenciada nos artigos analisados.

Dos 21 trabalhos avaliados, dez tinham como objeto de investigação temas relacionados ao PAT. Tais artigos apresentam abordagens diversificadas, que vão desde questões específicas até aspectos mais abrangentes acerca do alcance dos objetivos do Programa.

Moura (1986) avaliou o PAT no estado de Pernambuco, no que se refere a implantação, funcionamento e resultados em empresas, em estudo comparativo entre empresas inscritas e não inscritas no Programa, no período de 1977 a 1980. Ao analisar os cardápios oferecidos pelas empresas cadastradas, observou que apenas $15,8 \%$ atendiam às exigências energéticoproteicas. Em relação ao exame dos indicadores de impacto, os resultados sugeriram que não houve modificação no número de acidentes de trabalho, condições de saúde e rotatividade dos trabalhadores, tendo o Programa influído apenas na redução do absenteísmo. Ao contextualizar sua investigação, a autora referencia inúmeros estudos, realizados em diversas partes do mundo, que comprovam a inter-relação da ingestão calórica com a produtividade, evidenciando as implicações de um suprimento alimentar inadequado às necessidades vitais no rendimento do trabalho. Nas palavras de Moura,

a produtividade aumenta até o ponto em que a dieta é considerada adequada (para a superfície corporal, idade, sexo, clima, atividade e estado de saúde), não existindo evidências 
de que a adição de nutrientes melhore a saúde ou a eficiência de quem já está adequadamente alimentado. Isto evidencia a importância da alimentação no equilíbrio orgânico, não apenas como fator para a manutenção da saúde, mas, do ponto de vista econômico, como condição para maior dispêndio de energia e, consequentemente, maior capacidade de trabalho (p.115).

Ao analisar os motivos que levaram as empresas pernambucanas a ingressar no PAT, Moura (1986) relata que 70,59\% delas foram motivadas pelo incentivo fiscal, 12,94\%, pelo benefício social proporcionado ao empregado, 3,52\%, pela redução de atrasos e faltas e $2,36 \%$, para atender a solicitação governamental. Constatou, assim, que 76,47\% dos motivos relacionavam-se a benefícios para a própria empresa.

Veloso e Santana (2001) conduziram um estudo de coorte dinâmica retrospectiva com dados provenientes sobretudo de prontuários médicos on-line de trabalhadores do setor industrial, no período de 1996 a 2000. O estudo avaliou o impacto do PAT sobre o estado nutricional, encontrando associação positiva entre aumento de peso do trabalhador e empresa empregadora credenciada no Programa. Em 2007, com a mesma população de estudo, os autores demostraram que trabalhadores de empresas com PAT apresentavam níveis de triglicérides, colesterol total e glicemia mais elevados e maiores prevalências de hipertensão arterial sistólica, do que os não cobertos por programa de alimentação. Em relação ao ganho de peso, beneficiários de programas de alimentação apresentavam maiores taxas de incidência de ganho de peso e de sobrepeso, em comparação com trabalhadores não cobertos (Veloso, Santana, Oliveira, 2007).

Burlandy e Anjos (2001) trabalharam com dados da Pesquisa Sobre Padrões de Vida, inquérito populacional de base domiciliar realizado entre março de 1996 e março de 1997 nas regiões Nordeste e Sudeste do Brasil, para avaliar a relação entre acesso a vale refeição/ alimentação e estado nutricional de adultos beneficiários do PAT. A análise dos dados de avaliação nutricional indicou um quadro de sobrepeso importante $(38,5 \%$ de toda a população apresentou algum grau de sobrepeso), particularmente na região Sudeste (41,0\%) e na área urbana $(41,1 \%)$. A região Nordeste apresentou os percentuais mais elevados de baixo peso, totalizando $6,1 \%$, ao passo que no Sudeste esse valor foi de $4,2 \%$. Da população ocupada, 19,90\% recebiam vale refeição/alimentação ou cesta básica, sendo que o acesso a esse benefício foi maior na região Sudeste $(24,9 \%)$ do que na Nordeste $(11,7 \%)$, e maior na zona urbana do que na rural em ambas as regiões (15,8\% no Nordeste e 25,9\% no Sudeste). Os dados demonstraram também que indivíduos com sobrepeso - que em princípio não necessitariam do benefício, receberam mais esse auxílio do que aqueles com baixo peso (31,7\% e 23,5\%, respectivamente). O recebimento do benefício foi semelhante para os indivíduos com baixo peso em ambas as regiões (Nordeste, 23,6\% e Sudeste, 22,8\%), mas bastante diferenciado em relação aos que apresentaram sobrepeso (Nordeste, 16,8 e Sudeste, 38,4\%).

Sávio e colaboradores (2005) avaliaram o consumo alimentar do almoço e o estado nutricional de trabalhadores participantes do PAT no Distrito Federal, entre 2000 e 2001, com resultados que indicaram risco nutricional na população. A respeito do cardápio padrão, e em que pese serem as massas e carnes os pratos mais comuns em restaurantes selfservice, seus achados também corroboram os resultados de outros estudos que apontam o 
arroz e o feijão como itens básicos do padrão alimentar dos brasileiros. Em relação à avaliação antropométrica, observou-se que $43 \%$ dos trabalhadores apresentavam excesso de peso, sendo o percentual maior no sexo masculino $(48,1 \%)$ do que no feminino $(35,1 \%)$.

Tomando como foco de estudo os gestores, considerados os responsáveis pela alimentação do trabalhador em empresas cadastradas, um estudo conduzido em São Paulo evidenciou que grande parte dos gestores não identificou o PAT como política social de alimentação e nutrição. Apesar dos recentes esforços de acrescentar ao Programa a ideia de promoção da saúde e a exigência em educação alimentar, verificou-se que essas mensagens não foram ainda assimiladas pela maioria dos responsáveis por sua execução (Bandoni, Brasil, Jaime, 2006).

Em estudo sobre a concepção do PAT por parte dos trabalhores, considerando-se suas práticas discursivas, realizado em uma indústria do Rio Grande do Sul entre 2002 e 2003, concluiu-se que, a despeito de haver bom conhecimento das relações entre saúde e alimentação, o Programa em si é ignorado. A avaliação antropométrica revelou que 70,9\% dos trabalhadores apresentavam sobrepeso $(62,9 \%)$ ou obesidade $(8 \%)$, sendo que, pela análise da circunferência abdominal, $45,5 \%$ das mulheres e 14,8\% dos homens estavam com medidas que indicavam doenças cardiovasculares (Stolte, Hennington, Bernardes, 2006).

Com relação à visibilidade do PAT entre os trabalhadores, cabe salientar que o programa é de adesão voluntária pela empresa, de modo que os trabalhadores pouco podem influir a esse respeito, fato que, aliado ao desconhecimento sobre o programa por parte destes, agrava ainda mais a situação. Sobre esse aspecto, Santos e colaboradores (2007, p.1933, 1943) afirmam:

a participação dos trabalhadores, que vem se dando através das entidades representativas de classe de âmbito nacional na comissão instituída em 1997, pode ser entendida como um importante avanço da luta dos mesmos ao direito de participar das deliberações sobre a implementação do programa ...

Como visto neste estudo, o programa se mostrou pouco conhecido no grupo pesquisado, mesmo entre os que referiram trabalhar. Um maior envolvimento dos trabalhadores na gestão pode colaborar para alterar essa situação ... também se faz necessário maior divulgação de informações sobre o PAT junto à população alvo, de forma a conscientizar os trabalhadores sobre os seus direitos e as ações desenvolvidas pelo programa.

As mesmas autoras fizeram uma avaliação do programa trazendo reflexões importantes, apresentadas resumidamente a seguir:

Centralizado [o PAT], podendo ser exemplo de uma ação governamental essencialmente normativa, cuja lógica central foi modulada em um cenário social e econômico bastante diverso, pode-se dizer que o programa pouco mudou na medida em que não introduziu estratégias inovadoras que pudessem torná-lo mais adequado ao mundo do trabalho contemporâneo ... parte dos trabalhadores com renda abaixo de 5 salários mínimos está em empresas que não aderiram ao programa ou no mercado informal. Outra parcela importante de trabalhadores, principalmente em se tratando de alcançar os mais pobres, é representada pelos trabalhadores rurais, que ficam sem os benefícios gerados pelo programa, como constatado no presente estudo ... uma vez que a adesão ao programa é espontânea, boa parte das empresas, principalmente as pequenas e médias, sabidamente 
as que mais empregam no país, não se interessa pelo credenciamento. Isso parece indicar que a estrutura de incentivos do programa precisa ser revista ... historicamente, as mudanças normativas do programa concentraram-se na forma de participação das empresas, em prejuízo da discussão e revisão das recomendações nutricionais ... a inserção da educação alimentar reflete uma tentativa de deslocar a alimentação do trabalhador do foco genuinamente energético para um enfoque de promoção à saúde e/ou prevenção de enfermidades ... Faz-se necessário que a avaliação de programas se constitua em uma das atividades básicas e contínuas por parte do Governo. Isso permitiria uma reorientação e/ ou reformulação de suas estratégias, item este considerado falho na formulação do programa e que pode comprometer sobremaneira o alcance de seus objetivos (p.1942, 1943).

Recentemente, Geraldo, Bandoni e Jaime (2008) identificaram que a maioria dos cardápios oferecidos por empresas participantes do PAT na cidade de São Paulo teve baixa oferta de frutas e hortaliças $(63,9 \%)$ e gordura poli-insaturada $(83,3 \%)$, verificando-se, simultaneamente, excesso de gorduras totais $(47,2 \%)$ e colesterol $(62,5 \%)$. Concluíram os autores que é necessário uma ação direcionada aos gestores de empresas e responsáveis pelas unidades de alimentação e nutrição, principalmente no grupo de empresas que não tem a supervisão de nutricionista (uma exigência legal para se inscrever no Programa).

A avaliação antropométrica e a adequação dos cardápios oferecidos foram os itens mais avaliados nos diferentes estudos sobre o PAT, em distintos períodos estudados. Em relação ao perfil antropométrico, as pesquisas indicam um quadro de excesso de peso entre os usuários do Programa (Geraldo, Bandoni, Jaime, 2008; Veloso, Santana, Oliveira, 2007; Sávio et al., 2005; Veloso, Santana, 2001; Burlandy, Anjos, 2001); já em relação aos cardápios ofertados, indicam sua inadequação (Geraldo, Bandoni, Jaime, 2008; Sávio et al., 2005; Moura, 1986).

Ao que parece, o acesso dos trabalhadores à alimentação no trabalho, em empresas incentivadas pelo PAT, não garante o consumo de uma alimentação equilibrada do ponto de vista nutricional, o que pode afetar a saúde desses indivíduos. Estudos entre a população adulta brasileira, nas últimas décadas, vêm demonstrando uma mudança no perfil de morbimortalidade, com o sobrepeso e outros agravos nutricionais despontando nas estatísticas. As mudanças no padrão alimentar e o sedentarismo têm sido levantados como possíveis fatores explicativos para tais alterações. No entanto, Santos e colaboradores (2007) salientam que, por não se dispor de estudos epidemiológicos longitudinais para evidenciar a relação causa-efeito do PAT no estado de saúde e nutrição dos seus beneficiários, seria difícil imputar ao Programa mudanças no perfil nutricional da população trabalhadora adulta brasileira.

Pode-se perceber uma primazia do PAT como foco dos estudos relacionados à alimentação do trabalhador brasileiro. No entanto, há que considerar que uma parcela significativa de trabalhadores não é atendida pelo Programa, quer por não fazer parte do setor formal da economia - sabidamente os que em princípio mais necessitam -, ou por não pertencer a empresas cadastradas.

Em outras palavras, embora o PAT tenha sofrido algumas modificações desde sua criação, especialmente em termos das distintas estratégias de distribuição do benefício (que vão desde a oferta da alimentação em refeitórios da empresa, até o acesso, por meio de cartões magnéticos, a gêneros alimentícios in natura e/ou refeições em estabelecimentos 
credenciados), ainda deixa de atender algumas categorias, como trabalhadores rurais, autônomos e aqueles atuando no setor informal da economia. Ou seja, é um programa destinado à parcela bastante específica do trabalhador urbano com vínculo formal. Sendo assim, a população não beneficiada pelo Programa vê-se duplamente desprovida de uma relevante política pública de alimentação e nutrição, assim como de estudos científicos acerca de suas condições alimentares associadas ao seu trabalho.

Quanto ao material empírico analisado neste artigo, duas questões merecem destaque. A primeira diz respeito ao fato de a maior parte dos estudos ser desenvolvida no espaço da empresa, com trabalhadores que se alimentam no próprio local de trabalho e contam com apoio dos serviços de alimentação institucional. Denota-se, assim, a necessidade de mais estudos dirigidos às questões alimentares de outros grupos de trabalhadores brasileiros, os que não dispõem de uma estrutura de serviço de alimentação no espaço de trabalho. A segunda concerne à carência de análise da categoria 'trabalho' nas pesquisas sobre alimentação do trabalhador, o que inicialmente parece uma contradição. Boa parte dos autores analisa seus resultados à luz dos conhecimentos relativos a aspectos clínicos e biológicos, sem considerar adequadamente a dimensão do mundo do trabalho.

Cabe pontuar o estudo conduzido por Garcia (1997), que, a partir de análise do discurso de funcionários administrativos e de observação em lanchonetes e restaurantes na região central de São Paulo, explorou a dimensão da comida no modo de vida urbano, tendo em vista as implicações que esse modo de vida tem nos hábitos alimentares e nas representações simbólicas envolvidas. Concluiu a autora que, embora os aspectos simbólicos associados à alimentação tenham forte matriz afetiva, devido a sua origem no universo doméstico, as condições reais do meio urbano, associadas aos limites financeiros do sujeito estabelecem um arcabouço de valores e sentimentos compatíveis com suas possibilidades: "O meio urbano afeta a estrutura da alimentação e provoca uma reorganização de valores e práticas que, certamente, terão implicações no padrão alimentar. As pressões exercidas pelo meio urbano delineiam novas práticas que vão sendo incorporadas com resistência pelos comensais urbanos" (p.466).

Outro importante aspecto, relatado por Garcia (1997) diz respeito à abreviação dos rituais alimentares e suas implicações no comportamento alimentar. Há que se considerar que a alimentação no mundo moderno, principalmente nos grandes centros urbanos, é marcada pela rapidez no ato de alimentar-se devido ao pouco tempo a isso destinado. Nesse sentido, no cotidiano de trabalho extremamente acelerado, a ansiedade e a pressa podem interferir nas escolhas alimentares e nos modos de comer. Ocorre, então, a ruptura de tradições impondo novos modos de perceber o comer. Santos (2005), por sua vez, salienta que a praticidade e a rapidez impostas pela sociedade contemporânea acabam derrubando convenções construídas historicamente e pautadas pela tradição e pelos costumes:

As refeições feitas em conjunto, em casa, com horário determinado e um cardápio planejado estão se tornando cada vez mais raras ... No Brasil, os estudos e pesquisas têm demonstrado que, em função do fast-food, um novo padrão alimentar está se delineando, com prejuízos dos produtos da dieta tradicional do povo. O arroz, o feijão, a farinha de mandioca, que foram, desde o século XVIII, a base do cardápio da maioria da população, perdem cada vez mais espaço para os produtos industrializados e com maior valor agregado 
... A sociedade de consumo em massa faz com que se desestruturem os sistemas normativos e os controles sociais que regiam tradicionalmente as práticas e as representações alimentares (p.22-23).

É necessário analisar as questões até aqui assinaladas relacionando-as ao mundo do trabalho contemporâneo. Nessa perspectiva, sabe-se que, a partir dos anos 1980, vem ocorrendo um processo denominado reestruturação produtiva, o qual consiste em uma nova forma de produzir, organizar e gerenciar o trabalho num contexto de grandes avanços tecnológicos.

O avanço da tecnologia tem contribuído para a redução da exposição a alguns agentes de risco, ao mesmo tempo que acrescenta novos conteúdos ao trabalho, como intensificação do ritmo, sobrecarga psíquica, multiplicidade de funções e aumento de responsabilidades, entre outros. Antes a manufatura demandava do trabalhador um elevado gasto energético, considerando que sua própria energia era o mecanismo impulsor do trabalho. A mecanização e, mais recentemente, a automação reduziram drasticamente esse gasto. Não se despende mais grande esforço físico para a execução das tarefas, mas sim maior mobilização mental, que se apresenta como nova demanda de controle e monitorização do processo produtivo (Cohn, Marsiglia, 1993).

À complexidade desse 'novo' mundo do trabalho devem corresponder novas estratégias de alimentação do trabalhador, em que recomendações gerais, baseadas em cotas energéticas e de nutrientes, têm se mostrado ineficazes. Reconhece-se que o campo da alimentação do trabalhador é extremamente rico de possibilidades temáticas tanto na área da saúde quanto na das ciências sociais e humanas. Considerar as peculiaridades do processo de trabalho no planejamento alimentar é mais um desafio que se apresenta, e também aqui a ciência está em dívida com os trabalhadores.

\section{Considerações finais}

A despeito das conclusões já apontadas ao longo do texto, o presente artigo revela desafios importantes para pesquisadores, gestores e trabalhadores, no que diz respeito à alimentação. Primeiro, resta evidente que as estratégias voltadas para a alimentação do trabalhador parecem pouco efetivas, talvez porque pensadas sob um modelo alimentar e trabalhista dos anos 1940, incompatível, pois, com os dias em curso - os poucos estudos realizados, ainda que predominantemente de natureza epidemiológica, indicam que são incontestes os reflexos negativos sobre a saúde dos seus beneficiários. Desse modo, pensar políticas que incluam novos beneficiários e assegurem alimentação de qualidade é tarefa que precisa ser realizada.

Quanto às lacunas do conhecimento apresentadas, é necessário, além de mais pesquisas, a ampliação do período abordado nos estudos, bem como um incremento do arsenal metodológico utilizado. 


\section{REFERÊNCIAS}

BANDONI, Daniel Henrique; BRASIL, Bettina Gerken; JAIME, Patrícia Constante. Programa de Alimentação do Trabalhador: representações sociais de gestores locais. Revista de Saúde Pública, São Paulo, v.40, n.5, p.837- 842. Disponível em: http://www.scielos p.org/scielo.php?script=sci_arttext\&pid= S0034-89102006000600013\&lng=en\&nrm= iso\&tlng=pt. Acesso em: 8 jun.2008. 2006.

BOSI, Maria Lucia Magalhães.

A política de alimentação e nutrição pós-70. In: Bosi, Maria Lucia Magalhães. A face oculta da nutrição: ciência e ideologia. Rio de Janeiro: Espaço e Tempo; EdUFRJ. p.59-114. 1988.

BRAGA, José Carlos de Souza; PAULA, Sérgio Góes de.

Saúde e previdência: estudos de política social. São Paulo: Cebes; Hucitec. 1981.

BRASIL.

Ministério do Trabalho. Secretaria de Promoção Social. Tudo sobre o Programa de Alimentação do Trabalhador: manual e legislação. Brasília: Ministério do Trabalho. 1987.

BRASIL.

Ministério do Trabalho. Incentivos fiscais para a alimentação do trabalhador. Brasília: Secretaria de Promoção Social. (Coleção VII, Promoção Social). 1979.

BURLANDY, Luciene; ANJOS, Luiz Antonio dos. Acesso a vale-refeição e estado nutricional de adultos beneficiários do Programa de Alimentação do Trabalhador no Nordeste e Sudeste do Brasil, 1997. Cadernos de Saúde Pública, Rio de Janeiro, v.7, n.6, p.1457-1464. Disponível em: http://www.scielosp.org/ scielo.php?script=sci_arttext\&pid=S0102$311 \times 2001000600029 \& \operatorname{lng}=$ pt\&nrm=iso. Acesso em: 8 jun.2008. 2001.

CASCUDO, Luís da Câmara.

História da alimentação no Brasil. São Paulo: Global. 2004.

CASTRO, Ana Maria de. Nutrição e desenvolvimento: análise de uma política. Tese (Livre Docência em Sociologia) Instituto de Nutrição, Universidade Federal do Rio de Janeiro, Rio de Janeiro. 1977.

CASTRO, Josué de.

Geografia da fome (o dilema brasileiro: pão ou aço). São Paulo: Brasiliense. 1961.

COHN, Amélia; MARSIGLIA, Regina G. Processo e organização do trabalho. In: Rocha, Lys Esther; Rigotto, Raquel Maria; Buschinelli, José Tarcísio Penteado (Org.). Isto é trabalho de gente?: vida, doença e trabalho no Brasil. São Paulo: Vozes. p.56-75. 1993.

COIMBRA, Marcos.

Dois modelos de intervenção nutricional no Brasil: PNS e PROAB. In: Castro, Claudio de Moura; Coimbra, Marcos (Org.). O problema alimentar no Brasil. São Paulo: Editora da Unicamp. p.71-149. 1985.

DRAIBE, Sonia Mirian (Coord.).

Estratégias para o combate a pobreza no Brasil: programas, instituições e recursos. Relatório Final. Versão preliminar. Campinas: Núcleo de Estudos de Políticas Públicas/Unicamp. 1994.

FRIEDMANN, Georges; NAVILLE, Pierre. Traité de sociologie du travail. Paris: Armand Colin. 1962.

GAMBARDELLA, Ana Maria Diazeni. O Programa de Alimentação do Trabalhador frente às recomendações nutricionais para esse segmento específico da população: área metropolitana de São Paulo. Dissertação (Mestrado) - Faculdade de Saúde Pública, Universidade de São Paulo, São Paulo. 1990.

GARCIA, Rosa Wanda Diez.

Práticas e comportamento alimentar no meio urbano: um estudo no centro da cidade de São Paulo. Cadernos de Saúde Púbica, Rio de Janeiro, v.13, n.3, p.455-467. 1997.

GERALDO, Ana Paula Gines; BANDONI, Daniel Henrique; JAIME, Patrícia Constante. Aspectos dietéticos das refeições oferecidas por empresas participantes do Programa de Alimentação do Trabalhador na cidade de São Paulo, Brasil. Revista Panamericana de Salud Publica, Washington, v.23, n.1, p.19-25. Disponível em: http://www.scielosp.org/ scielo.php?script=sci_arttext\&pid=S1020$49892008000100003 \& \operatorname{lng}=$ pt\&nrm=iso. Acesso em: 8 jun.2008. 2008.

L'ABBATE, Solange.

As políticas de alimentação e nutrição no Brasil: I - período de 1940 a 1964. Revista de Nutrição da Puccamp, Campinas, v.1, n.2, p.87-138. 1988.

MERLO, Álvaro Roberto Crespo; LÁPIS, Naira Lima.

A saúde e os processos de trabalho no capitalismo: reflexões na interface da psicodinâmica do trabalho e da sociologia do trabalho. Psicologia \& Sociedade, Porto Alegre, v.19, n.1, p.61-68. Disponível em: http:// www.scielo.br/scielo.php?script= sci_arttext\&pid=S0102-71822007000100009 $\& \ln g=$ en\&nrm=iso. Acesso em: 8 jun. 2008. 2007. 
MOURA, Josenilda Barros de.

Avaliação do Programa de Alimentação do Trabalhador no Estado de Pernambuco, Brasil. Revista de Saúde Pública, v.20. n.2. p.115-128. 1986.

MURRIETA, Rui Sérgio Sereni.

Dialética do sabor: alimentação, ecologia e vida cotidiana em comunidades ribeirinhas da ilha de Ituqui, Baixo Amazonas, Pará. Revista de Antropologia, São Paulo, v.44, n.2, p.39-88. Disponível em: http://www.scielo.br/ scielo.php?script=sci_arttext\&pid=S0034$77012001000200002 \& \operatorname{lng}=\mathrm{en} \& \mathrm{nrm}=\mathrm{iso} \& \mathrm{t} \operatorname{lng}=\mathrm{pt}$. Acesso em: 12 abr. 2007. 2001.

PELIANO, Ana Maria Tibúrcio Medeiros et al. O problema alimentar brasileiro: situação atual, perspectivas e proposta de políticas. In: Castro, Claudio de Moura; Coimbra, Marcos (Org). O problema alimentar no Brasil. São Paulo: Editora da Unicamp. p.15-43. 1985.

PESSOA, Raimundo Agnelo Soares.

O escravo negro nos primeiros escritos coloniais (1551-1627). Saeculum, Revista de História, João Pessoa, v.13, p.21-38. 2005.

PÔRTO, Ângela.

O sistema de saúde do escravo no Brasil do século XIX: doenças, instituições e práticas terapêuticas. História, Ciências, Saúde Manguinhos, Rio de Janeiro, v.13, n.4, p.10191127. Disponível em: http://www.scielo.br/ scielo.php?script=sci_arttext\&pid=S0104$59702006000400013 \& \operatorname{lng}=e n \& n r m=$ iso. Acesso em: 8 jun. 2008. 2006.

POSSAS, Cristina de Albuquerque.

Saúde e trabalho: a crise da previdência social. Rio de Janeiro: Graal. 1981.

RODRIGUES, Jaime.

Alimentação popular em São Paulo (1920 a 1950): políticas públicas, discursos técnicos e práticas profissionais. Anais do Museu Paulista, São Paulo, v.15. n.2, p.221-255. Disponível em: http://www.scielo.br/scielo.php?script= sci_arttext\&pid=S0101-47142007000 $200019 \& \operatorname{lng}=\mathrm{pt} \& n r m=\mathrm{iso} \& \operatorname{lng}=\mathrm{pt}$. Acesso em: 2 jun. 2008. 2007.

SANTOS, Carlos Roberto Antunes dos. A alimentação e seu lugar na história: os tempos da memória gustativa. História: Questões \& Debates, Curitiba, v.22 n.42, p.11-31. 2005.

SANTOS, Leonor Maria Pacheco et al. Avaliação de políticas públicas de segurança alimentar e combate à fome no período 19952002: Programa de Alimentação do Trabalhador. Cadernos de Saúde Pública, Rio de Janeiro, v.23, n.8, p.1931-1945. Disponível em: http://www.scielosp.org/scielo.php?pid=S0102-
$311 X 2007000800020 \& s c r i p t=s c i$ arttext $\& \ln g=e s$. Acesso em: 8 jun.2008. 2007.

SÁVIO, Karin Eleonora Oliveira et al. Avaliação do almoço servido a participantes do Programa de Alimentação do Trabalhador. Revista de Saúde Pública, São Paulo, v.39, n.2, p.148-155. Disponível em: http:// www.scielosp.org/scielo.php?script $=$ sci arttext\&pid=S0034-89102005000 200002\&lng=pt. Acesso em: 8 jun.2008. 2005.

SILVA JÚNIOR, Sinézio Inácio.

Economia e nutrição. In: Dutra de Oliveira, José; Marchini, Julio Sérgio (Org.). Ciências nutricionais. São Paulo: Sarvier. p.305-319. 1998.

STOLTE, Desire; HENNINGTON, Élida Azevedo; BERNARDES, Jefferson de Souza. Sentidos da alimentação e da saúde: contribuições para a análise do Programa de Alimentação do Trabalhador. Cadernos de Saúde Pública, Rio de Janeiro, v.22, n.9, p.1915-1924.

Disponível em: http://www.scielosp.org/ scielo.php?script=sci arttext\&pid=S0102$311 \times 2006000900023 \& \operatorname{lng}=$ en $\& n r m=i s o \& t \operatorname{lng}=$ pt. Acesso em: 8 jun.2008. 2006.

VARGAS, Nilton.

Gênese e difusão do taylorismo no Brasil. In: Anpocs. Ciências Sociais Hoje. Anuário de antropologia, política e sociologia. São Paulo: Cortez. p.155-190. 1985.

VASCONCELOS, Francisco de Assis Guedes de. Tendências históricas dos estudos dietéticos no Brasil. História, Ciências, Saúde-Manguinhos, Rio de Janeiro, v.14, n.1, p.197-219. Disponível em: http://www.scielo.br/scielo.php?script= sci_arttext\&pid=S0104-59702007000 $100010 \& \operatorname{lng}=$ en $\&$ nrm=iso. Acesso em: 8 jun.2008. 2007.

VASCONCELOS, Francisco de Assis Guedes de. Combate à fome no Brasil: uma análise histórica de Vargas a Lula. Revista de Nutrição, Campinas, v.18, n.4, p.439-457. Disponível em: http://www.scielo.br/scielo.php?script= sci_arttext\&pid=S1415-527320050004 $00001 \& \operatorname{lng}=e n \& n r m=i s o$. Acesso em: 8 jun. 2008. 2005.

VASCONCELOS, Francisco de Assis Guedes de. O nutricionista no Brasil: uma análise histórica. Revista de Nutrição, Campinas, v.15, n.22, p.127-138. Disponível em: http://www.scielo.br/ scielo.php?script=sci_arttext\&pid=S1415$52732002000200001 \& \operatorname{lng}=$ en $\& n r m=i s o$. Acessado em: 8 jun. 2008. 2002.

VASCONCELOS, Francisco de Assis Guedes de. Fome, eugenia e constituição do campo da nutrição em Pernambuco: uma análise de Gilberto Freyre, Josué de Castro e Nelson 
Maria da Purificação N. Araújo, Jamacy Costa-Souza, Leny Alves B. Trad

Chaves. História, Ciências, Saúde - Manguinhos, Rio de Janeiro, v.8, n.2, p.315-339. Disponível em: http://www.scielo.br/scielo.php?script= sci_arttext\&pid=S0104-59702001000 $300002 \& \operatorname{lng}=e n \& n r m=i s o$. Acesso em: 8 jun. de 2008. 2001.

VASCONCELOS, Francisco de Assis Guedes de; SANTOS, Leonor Maria Pacheco.

Tributo a Manoel da Gama Lobo (1835-1883), pioneiro na epidemiologia da deficiência de vitamina A no Brasil. História, Ciências, Saúde Manguinhos, Rio de Janeiro, v.14, n.4, p.13411356. Disponível em: http://www.scielo.br/ scielo.php?script=sci_arttext\&pid=S0104$59702007000400013 \& \operatorname{lng}=$ en\&nrm=iso . Acesso em: 08 jun.2008. 2007.
VELOSO, Iracema Santos; SANTANA, Vilma Souza.

Impacto nutricional do programa de alimentação do trabalhador no Brasil. Revista Panamericana de Salud Pública, Washington, v.11, n.1, p.24-31. Disponível em: http:// www.scielosp.org/scielo.php?pid=S1020$49892002000100004 \&$ script=sci_arttext. Acesso em: 8 jun.2008. 2002.

VELOSO, Iracema Santos; SANTANA, Vilma Souza; OLIVEIRA, Nelson Fernandes.

Programas de alimentação para o trabalhador e seu impacto sobre ganho de peso e sobrepeso. Revista de Saúde Pública, São Paulo, v.41, n.5, p.769-776. Disponível em: http:// www.scielosp.org/scielo.php?script=sci_arttext \&pid=S0034-89102007000500011\&lng=pt. Acesso em: 8 jun.2008. 2007.

\section{$\rightarrow \rightarrow \rightarrow<<<$}

